\title{
Mass movements inventory map of the Rubbio stream catchment (Basilicata, South Italy)
}

\author{
Massimo Conforti *, Stefania Pascale** \& Francesco Sdao**
}

${ }^{*}$ CNR - Istituto per Sistemi Agricoli e Forestali del Mediterraneo (ISAFOM), Rende (CS), Italy (massimo.conforti@isafom.cnr.it)

** Scuola di Ingegneria, Università della Basilicata, Potenza, Italy (pascalestefania@gmail.com, francesco.sdao@unibas.it)

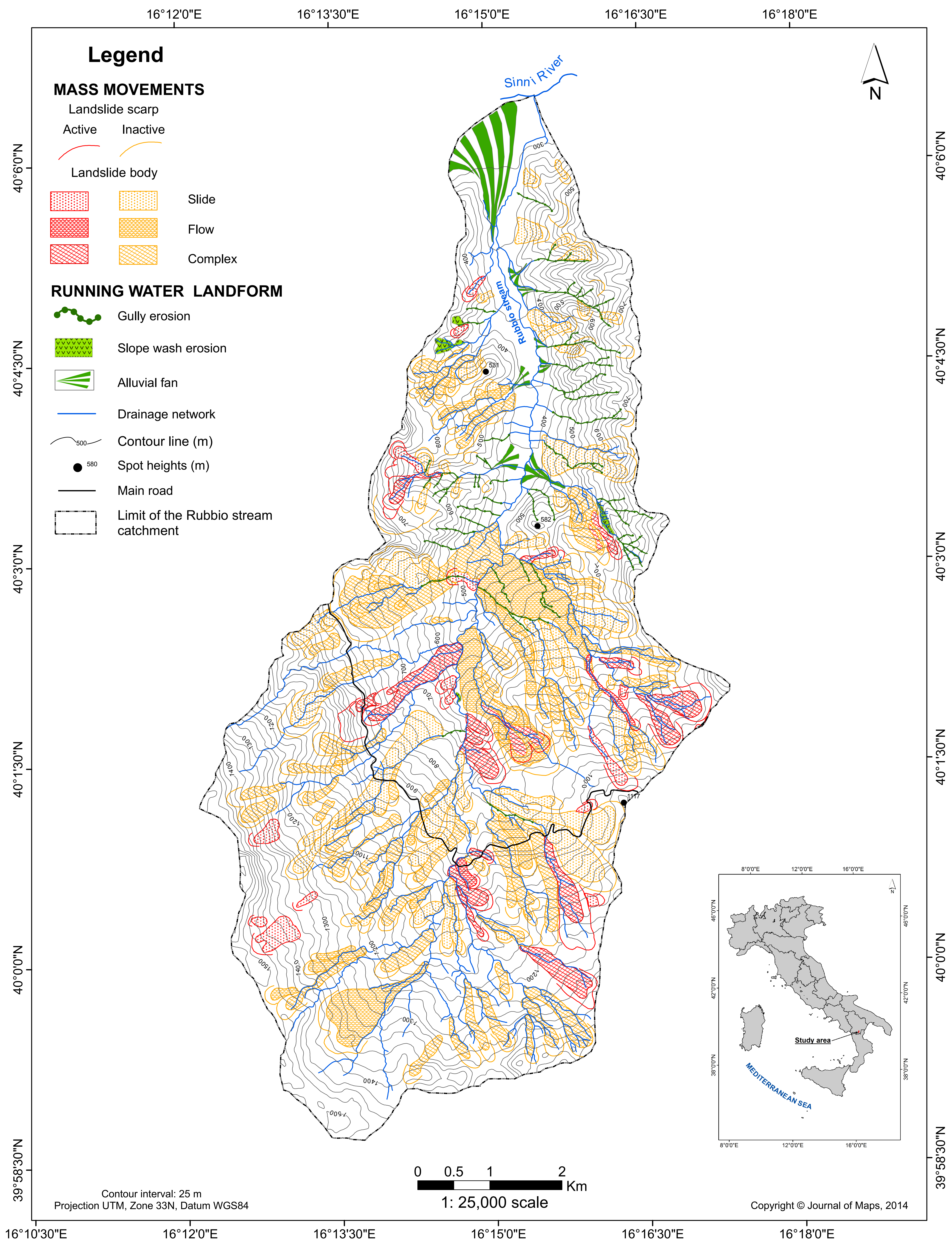

